\title{
Specific resistance upon lentiviral TRAIL transfer by intracellular retention of TRAIL receptors
}

\author{
T Wenger ${ }^{1}$, J Mattern ${ }^{1,2}$, R Penzel ${ }^{3}$, N Gassler ${ }^{4}$, TL Haas ${ }^{5}$, \\ MR Sprick ${ }^{5}$, H Walczak ${ }^{5}$, PH Krammer ${ }^{6}$, K-M Debatin ${ }^{7}$ and \\ I Herr*,1,7,8 \\ 1 Research Group Molecular Urooncology, German Cancer Research Center, \\ Heidelberg, Germany \\ 2 Clinical Cooperation Unit Nuclear Medicine, German Cancer Research Center, \\ Heidelberg, Germany \\ 3 Department of Pathology, University of Heidelberg, Heidelberg, Germany \\ ${ }^{4}$ Institute of Pathology, University of Aachen, Aachen, Germany \\ 5 Division of Apoptosis Regulation, German Cancer Research Center, \\ Heidelberg, Germany \\ ${ }^{6}$ Division of Immunogenetics, German Cancer Research Center, Heidelberg, \\ Germany \\ 7 Department of Pediatrics, University of Ulm, Ulm, Germany \\ 8 Department of Urology, University of Heidelberg, Heidelberg, Germany \\ * Corresponding author: I Herr, Professor of Experimental Medicine, German \\ Cancer Research Center, Molecular Urooncology, E095, Im Neuenheimer \\ Feld 280, 69120 Heidelberg, Germany. Tel: + 49 6221/42 3366; \\ Fax: + 496221 3362; E-mail: i.herr@dkfz.de
}

Received 08.7.05; revised 22.12.05; accepted 22.12.05; published online 10.2.06 Edited by GM Cohen

\begin{abstract}
Tumor necrosis factor-related apoptosis-inducing ligand (TRAIL) selectively induces apoptosis in many transformed cells, suggesting TRAIL as an ideal candidate for cancer gene therapy. A main obstacle in cancer therapy is intrinsic or acquired therapy resistance of malignant cells. To study induction of resistance against TRAIL, we generated lentiviral vectors allowing efficient TRAIL expression and apoptosis induction in a variety of human cancer cell lines. Within days upon TRAIL overexpression, cells became resistant towards TRAIL, but not to CD95 ligation or DNA damage by cisplatin. Cell surface expression of TRAIL receptors 1 and 2 was completely abrogated in resistant cells due to intracellular retention of the receptors by TRAIL. SiRNA directed against TRAIL resensitized the resistant cells by restoring cell surface expression of TRAIL receptors. These findings represent a novel resistance mechanism towards TRAIL, specifically caused by TRAIL overexpression, and question the use of TRAIL expression in tumor-cell targeting gene therapy.

Cell Death and Differentiation (2006) 13,1740-1751. doi:10.1038/sj.cdd.4401867; published online 10 February 2006
\end{abstract}

Keywords: lentiviral vector; resistance mechanism; cancer therapy; gene therapy; TRAIL

Abbreviations: AAV, adeno-associated virus; LV, lentivirus; Ad, adenovirus; MOI, multiplicity of infection; DISC, death-inducing signaling complex; DR, death receptor; TNF, tumor necrosis factor; TRAIL, TNF-related apoptosis-inducing ligand; TRAIL-R, TRAIL-receptor; AZT, azidothymidine; s, soluble; fl, full length; LZ, leucine zipper

\section{Introduction}

The death ligand tumor necrosis factor (TNF)-related apoptosis-inducing ligand (TRAIL) (also known as Apo2L) is a potent inducer of apoptosis in transformed cells, while sparing most normal cell types. Therefore, the recombinant protein, as well as the gene itself expressed by adenovirus- or adenoassociated virus (AAV)-derived vectors, ${ }^{1-3}$ have been widely used in preclinical cancer models. ${ }^{4-7}$ As some publications raised concerns about liver toxicity of certain recombinant TRAIL preparations ${ }^{8}$ and demonstrated the expression of TRAIL receptors in human brain tissue ${ }^{9}$ gene therapy using local administration of virus may be particularly advantageous, as it can generate high concentrations of TRAIL only locally. Apoptotic TRAIL signaling occurs via the two TRAIL death receptors, TRAIL-receptor 1 (TRAIL-R1, also known as Death Receptor 4, DR4) and TRAIL-receptor 2 (TRAIL-R2, also known as DR5). ${ }^{10}$ Similarly to CD95, the TRAIL death receptors oligomerize upon engagement by the ligand and form a death inducing signaling complex (DISC) by recruiting FADD, caspase- 8 and -10 , and FLIP. ${ }^{11}$ At the DISC, caspase8 is autocatalytically activated. Further caspases are either directly cleaved and activated by caspase-8 or by Bidmediated engagement of the mitochondrial apoptosis pathway. ${ }^{12}$ Three receptors devoid of complete intracellular death domains (TRAIL-R3/DcR1, TRAIL-R4/DcR2, and OPG) have been suggested to be decoy receptors and to act as modulators of TRAIL sensitivity.

In a recent report, we used an inducible TRAIL-overexpressing cell line for paracrine apoptosis induction in human cancer cells. ${ }^{13}$ While generating this cell line, we observed that cells rapidly acquired TRAIL resistance. Similarly, the development of TRAIL resistance has been reported upon repeated administration of recombinant TRAIL or TRAILexpressing Ad over long periods of time ${ }^{14-16}$ However, the biochemical mechanism responsible for this acquired resistance remains elusive. To study the mechanism of resistance induction upon TRAIL overexpression and under constant TRAIL exposure, we chose lentiviral gene transfer of TRAIL. HIV-derived VSV-G-pseudotyped lentiviral vectors mediate stable, high-level transgene expression in both dividing and nondividing cells and tissues from a wide range of organisms in vitro and in vivo. ${ }^{17,18}$ These properties have made them an attractive tool for research and therapeutic applications. This gene transfer system enabled us to monitor resistance induction using a bulk culture of transduced cells without further selection pressure, due to stable expression in all transduced cells. Stable expression upon transfection, in contrast, is achieved by antibiotic selection of clones, and especially the tight regulation of expression using inducible systems relies upon single clones with the desired properties. These clones are often not suitable for the study of resistance mechanisms, as they do not represent the whole population of cells. In this report, we describe the transduction of human cancer cell lines with a TRAIL-expressing lentiviral vector. 
TRAIL expression resulted in induction of apoptosis mediated by membrane-bound TRAIL. Owing to the stable expression of TRAIL protein, we observed a novel mechanism of resistance towards TRAIL-mediated apoptosis, caused directly by TRAIL overexpression. Intracellular retention of TRAIL death receptors, most likely by interaction with the ligand, resulted in complete and specific resistance of transduced cells. These findings shed new light on the feasibility and efficacy of TRAIL gene therapy and prompt the reconsideration of TRAIL overexpression, at least in tumor cells themselves, as a therapeutic approach.

\section{Results}

\section{Production of LV.TRAIL and transduction of human tumor cell lines}

We generated lentiviral vectors for expression of GFP alone (LV.GFP), of full length (FL) human TRAIL together with GFP (LV.TRAIL), and of a TRAIL-GFP fusion protein (LV.GFPTRAIL) (Figure 1a). We evaluated the vectors using the FADD-DN expressing variant of the human $B$ cell lymphoma cell line BJAB, in which the death receptor pathway is blocked, to avoid possible disturbance of the assay by apoptosis induction by TRAIL. Upon transduction of BJABFADD-DN cells, LV.TRAIL- but not LV.GFP-transduced cells showed TRAIL surface expression, as detected by flow cytometry after $24 \mathrm{~h}$ (Figure $1 \mathrm{~b}$ ). However, only $33 \%$ of cells had detectable surface expression of TRAIL, especially in the highly GFP-positive population, although over $80 \%$ of cells were transduced with LV-TRAIL, as measured by GFP expression. Inhibition of reverse transcription by the addition of Azidothymidine (AZT) reduced the level of GFP expression upon LV.GFP- and LV.TRAIL-transduction at least 10-fold (data not shown), demonstrating specificity of lentiviral gene expression. Upon transduction of normal BJAB-cells, LV.TRAIL but not LV.GFP-induced apoptosis in about $20 \%$ of the cells, which was reduced in the presence of AZT (Figure 1c). BJAB-FADD-DN cells with a defect in death receptor signaling were not susceptible to LV.TRAIL-induced apoptosis, as expected. Previous reports have described the carryover of proteins expressed in producer cells by enveloped viral particles, ${ }^{19}$ causing transduction-independent induction of apoptosis. To investigate the possibility of partial apoptosis induction by LV.TRAIL-particles containing TRAIL protein, we performed immunoprecipitation analysis of LV.GFP and LV.TRAIL using a TRAIL-specific antibody (1d). Western blot analysis revealed that LV.TRAIL- but not LV.GFP-particles contained full-length human TRAIL protein. HIV-1 gag p24, which unfortunately appears in the Western blot at the same molecular weight as the IgG light chain, was co-precipitated, confirming that indeed the virus particles themselves contain some TRAIL protein.

These data demonstrate that LV.TRAIL can mediate TRAIL surface expression in human tumor cells and cause both transduction-dependent apoptosis due to TRAIL expression and transduction-independent apoptosis due to TRAIL protein carryover.
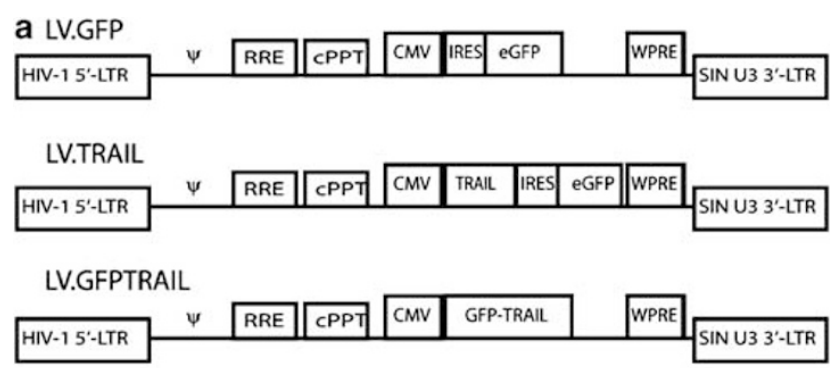

b

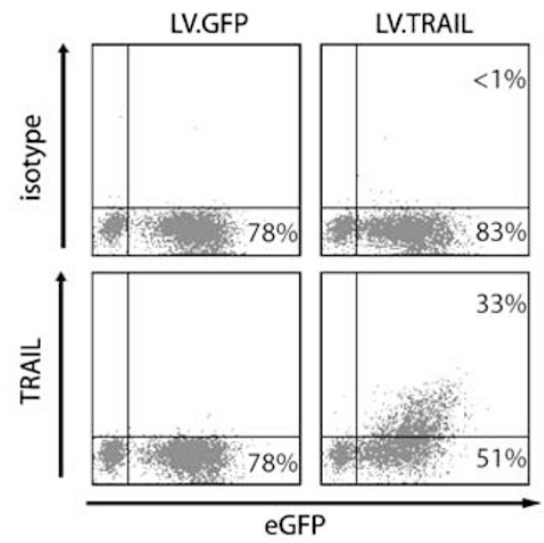

C

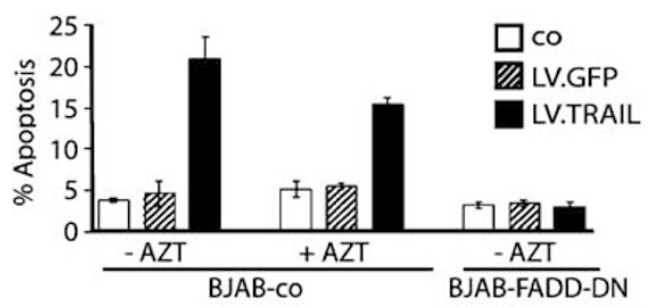

d

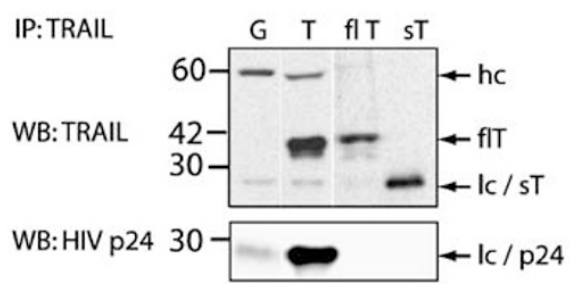

Figure 1 Lentiviral gene transfer mediates TRAIL expression and apoptosis. TRAIL protein is present on TRAIL-expressing lentiviral particles. Co: no virus, GFP: LV.GFP, TRAIL: LV.TRAIL. (a) Structure of the lentiviral constructs, LV.GFP (expressing eGFP), LV.TRAIL (expressing TRAIL and GFP), and LV.GFPTRAIL (expressing an eGFP-TRAIL fusion protein). (b) GFP and TRAIL expression in BJAB FADD-DN cells upon transduction at MOI 2.5 was determined by staining with anti-TRAIL-antibody and PE-conjugated secondary antibody. Numbers given in the dot plots are the percentage of cells in the respective quadrants. (c) Apoptosis in BJAB control and FADD-DN cells was measured by Nicoletti staining $48 \mathrm{~h}$ after transduction at MOI 0.5 with LV.GFP and LV.TRAIL in the presence and absence of AZT. (d) $1 \times 10^{6} \mathrm{IU}$ of LV-GFP (G) or LV-TRAIL (T) were immunoprecipitated using an anti-TRAIL antibody and Protein G-Agarose and analyzed by SDS-PAGE and Western blot using antiTRAIL and anti-HIV p24 antibodies. Lysate of 293T cells expressing full-length human TRAIL (fl T) and recombinant S TRAIL (sT) were used as controls. (hc): mlgG heavy chain, (IC): mlgG light chain

\section{Paracrine apoptosis induction by membrane-bound TRAIL}

To confirm that TRAIL expressed on transduced cells was biologically active, we co-cultured transduced BJAB cells with 
parental or caspase-8-deficient Jurkat cells at a ratio of 10:1. Target cells were identified by CD3 staining. Massive apoptosis of approximately $80 \%$ was found in parental, but not in caspase-8-deficient Jurkat cells upon co-culture with TRAIL-expressing effector cells only (Figure 2a). TRAIL can be expressed as a membrane-bound or a soluble (s) form. The production of $S$ TRAIL was reported to involve protease cleavage of FL TRAIL ${ }^{20}$ or vesicle secretion. ${ }^{21}$ The precise mode of sTRAIL production is still unclear, but in most cases requires stimulation of cells ${ }^{22}$ and release of stored STRAIL ${ }^{23}$ rather than just shedding of the extracellular domain of cell surface expressed fITRAIL. To confirm that the biologically active TRAIL was indeed the membrane-bound form in our setting, we used BL-60 cells as a target. This human B-cell line is highly sensitive towards TRAIL-mediated apoptosis ${ }^{24}$ and thus represents an excellent indicator system. To prevent cell-cell contact, we co-cultured BL-60 cells in the upper chamber of a $0.2 \mu \mathrm{m}$ transwell plate with LV.GFP- and LV.TRAIL-transduced BJAB or P693 cells in the lower chamber. Medium containing $30 \mathrm{ng} / \mathrm{ml}$ recombinant TRAIL, which is able to pass the membrane of the two-chamber system, was used as a control. After $24 \mathrm{~h}$, induction of cell death by TRAIL-transduced cells was not detected (Figure 2b), while recombinant TRAIL induced apoptosis. These data suggest that lentiviral TRAIL expression specifically induces death receptor-mediated apoptosis, and that membrane-bound TRAIL is important for the induction of apoptosis in neighbouring cells in this system.

a

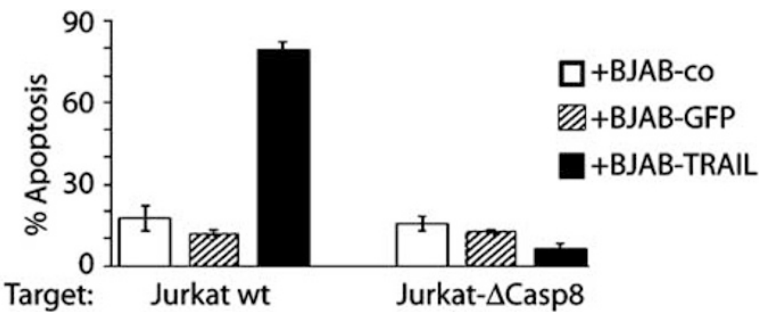

b

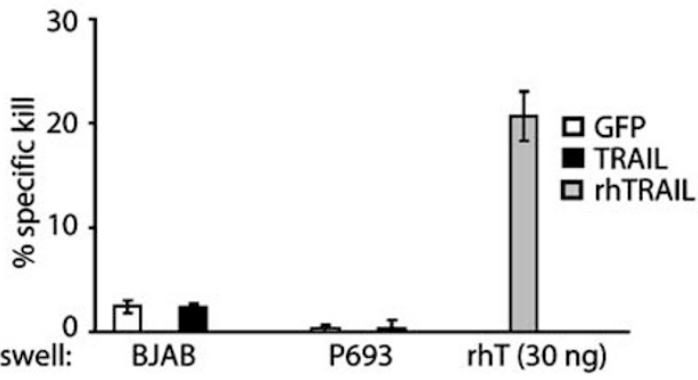

Figure 2 TRAIL expressed on the surface of transduced cells, but not $s$ TRAIL mediates paracrine apoptosis. (a) BJAB cells were transduced at $\mathrm{MOI} 0.5$ and cultured for 5 days. LV.GFP- and LV.TRAIL-transduced and nontransduced cells were co-cultured with wild-type or caspase-8 deficient Jurkat cells at a 10:1 ratio, $\left(2 \times 10^{5}\right.$ total cells in $200 \mu$ lin 96 well-plates $)$ for $24 \mathrm{~h}$. The cells were stained with anti-CD3-CyChrome and AnnexinV-PE. Target cells were CD3-CyChrome ${ }^{+}$ GFP. (b) BL-60 cells were co-cultured in $0.2 \mu \mathrm{m}$ transwell plates with transduced P693and BJAB cells, or fresh medium containing $30 \mathrm{ng} / \mathrm{ml}$ recombinant TRAIL (rhT), and the specific apoptosis was measured by FSC/PI

\section{Development of resistance and outgrowth of transduced cells}

Upon culture of transduced BJAB cells for 30 days, we observed an increase of GFP-expressing cells from initially 46 to $98 \%$ in LV.TRAIL-transduced cells (Figure $3 a$ ). In the LV.GFP- and LV.TRAIL-transduced FADD-DN BJAB cells, the percentage of GFP expressing cells remained unchanged. Upon outgrowth, cells acquired complete resistance towards TRAIL, while retaining normal sensitivity towards CD95 stimulation and the DNA-damaging drug cisplatin (Figure $3 b$ ). TRAIL expressed by resistant cells remained biologically active, since Jurkat target cells were still killed in co-culture assays (data not shown). To further highlight the time course of development of resistance to TRAIL-induced apoptosis by lentiviral overexpression of TRAIL, BJAB cells were transduced at high MOI (2.5) with LV.GFP or LV.TRAIL in the presence of the caspase-inhibitor zVAD-fmk, to avoid apoptosis induction by the TRAIL protein present in the viral particles. After $24 \mathrm{~h}, \mathrm{zVAD}-\mathrm{fmk}$ was removed by extensive washing and adding fresh medium. After $48 \mathrm{~h}$, the cells were treated with anti-APO-1 or TRAIL for $24 \mathrm{~h}$. While TRAILinduced apoptosis was strongly diminished in LV.TRAILtransduced cells, LV.GFP- and LV.TRAIL-transduced cells were equally sensitive to CD95-induced apoptosis (Figure 3c), suggesting that selective resistance towards lentiviral TRAIL occurs as early as $96 \mathrm{~h}$ after transduction. Quite similar results were obtained by transducing the established human lung (P693), cervical (P5), and pancreatic (MIAPACA) cancer cell lines with LV.TRAIL and LV.GFP. This resulted in $20-40 \%$ transduced cells $72 \mathrm{~h}$ post-transduction (Figure 3d). At 30 days after transduction with LV.TRAIL the percentage of GFP-expressing cells had increased to 80-100\% while the percentage of GFP-expressing cells in LV.GFP-transduced cells remained unchanged. This was accompanied by complete resistance towards TRAIL in the TRAIL transduced cells (Figure $3 e$ ). These results suggest that lentiviral overexpression of TRAIL resulted in selective TRAIL resistance of transduced cells and outgrowth of the resistant population, via a non-cell-type-specific mechanism.

\section{Mechanism of resistance}

To investigate the mechanism of selective TRAIL resistance, we treated transduced cells with recombinant human leucine zipper (LZ)-TRAIL and the CD95-crosslinking anti-APO-1 antibody as a positive control and examined death receptor activation by Western blot analysis of caspase-8 cleavage. Whereas control cells cleaved caspase-8 upon CD95 and TRAIL stimulation, LV.TRAIL-transduced resistant cells failed to process procaspase-8 upon TRAIL stimulation, but showed normal processing upon CD95 activation (Figure 4a). As caspase cleavage does not necessarily translate into caspase activity, we also tested for caspase-8 activity. Activation of caspase-8 was confirmed by an enzymatic activity assay (Figure 4b). Levels of total caspase-8 and c-FLIP were examined by Western blot analysis and were unchanged in the resistant cells (Figure 4c). To determine surface expression of TRAIL receptors, we performed FACS analysis using 
a

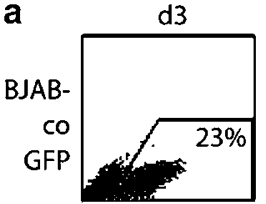

$\mathrm{d} 30$

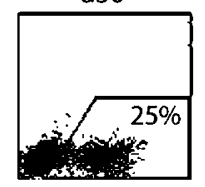

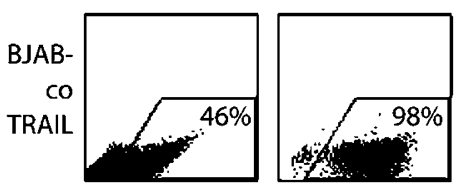

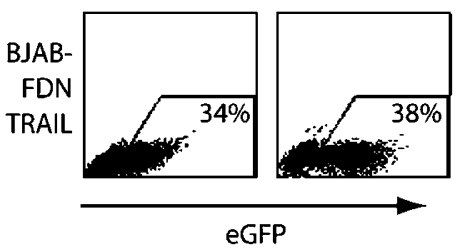

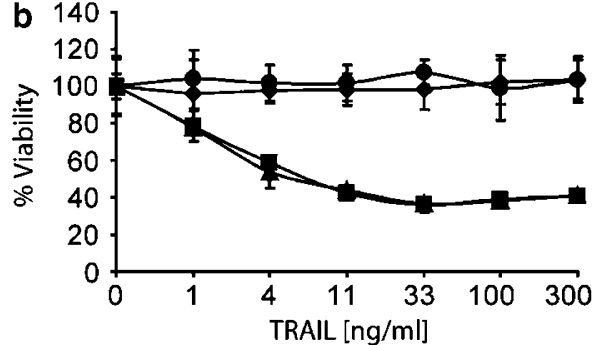
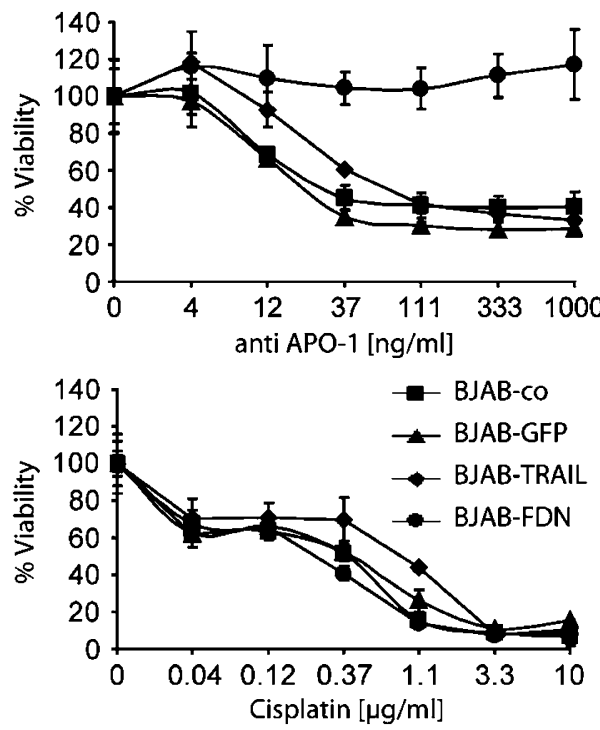
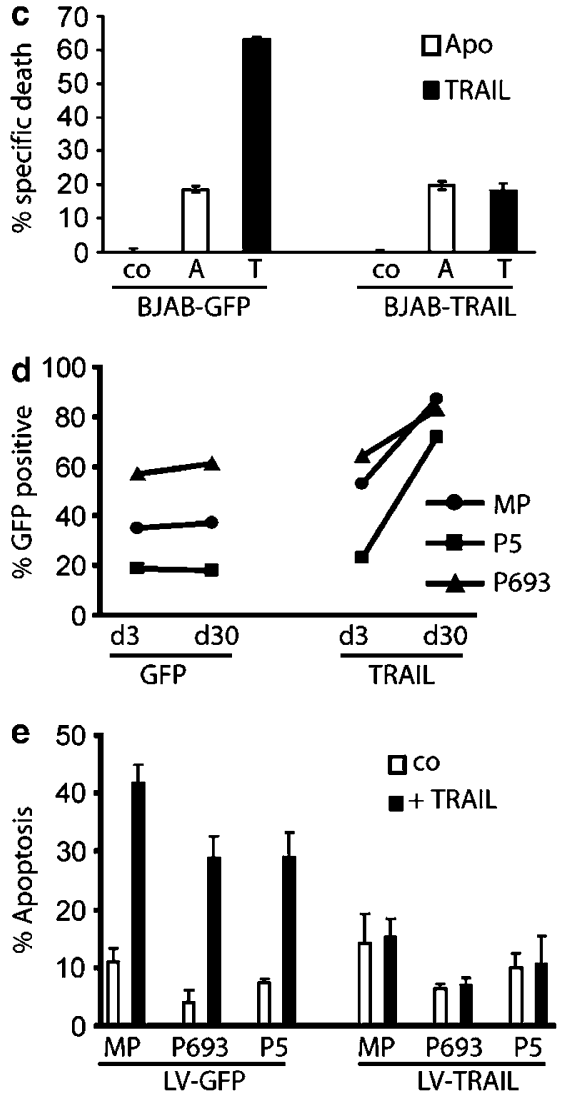

Figure 3 TRAIL transduced cells specifically grow out due to resistance to TRAIL but not to CD95 stimulation or cisplatin. (a) GFP expression on day 3 and 30 posttransduction of BJAB cells transduced at MOI 0.5. (b) BJAB cells 30 days after transduction were stimulated for $24 \mathrm{~h}$ with recombinant TRAIL and anti-APO-1 or for $72 \mathrm{~h}$ with cisplatin at the indicated concentrations. Cell death was measured by MTT assay. Co: no virus, GFP: LV.GFP, TRAIL: LV.TRAIL, FDN: BJAB-FADD-DN. (c) BJAB cells were transduced in the presence of ZVAD-fmk at MOI 2.5. After $24 \mathrm{~h}, \mathrm{ZVAD}$-fmk was removed, and cells were stimulated $72 \mathrm{~h}$ after transduction for $24 \mathrm{~h}$ with antiAPO-1 (A) or TRAIL (T) at $100 \mathrm{ng} / \mathrm{ml}$. Apoptosis was analyzed by FSC/PI. (d) P693, MIAPACA (MP) and P5 cells were transduced with LV.GFP and LV.TRAIL. GFP expression was measured at day 3 and 30 after transduction. (e) Transduced cells (day 30 after transduction) were stimulated with TRAlL (1 $\mu \mathrm{g} / \mathrm{ml})$ for $48 \mathrm{~h}$ and apoptosis was measured by Nicoletti staining

BJAB cells 30 days after transduction (Figure $4 d$ ) since the outgrowth observed in the LV.TRAIL-transduced BJAB wildtype cells was complete at this timepoint. While cell surface expression of TRAIL-R1 and TRAIL-R2 could be detected in BJAB-control and BJAB-FADD-DN cells transduced with GFP alone, expression was absent in TRAIL-expressing parental BJAB cells and in the high-GFP-expressing population of FADD-DN cells transduced with LV.TRAIL. The analysis of BJAB-FADD-DN-cells transduced at different $\mathrm{MOI}$ and expressing different amounts of TRAIL demonstrated that TRAIL-R1 and TRAIL-R2 expression was downregulated depending on the amount of TRAIL surface expression. Expression of TRAIL-R3 and TRAIL-R4 was not detectable in BJAB cells (data not shown) as described. ${ }^{24}$ TRAIL expression could be detected in the high-GFP-expressing population of LV.TRAIL-transduced parental BJAB and FADD-DN cells. CD95 levels were examined as a control and remained unchanged excluding a general interference with protein transport in transduced cells. BJAB cells transduced with LV.GFP at higher MOI did not show any differences compared to the ones transduced at lower MOI (data not shown). Similar results were obtained with LV.GFP- and LV.TRAIL-transduced P693 cells (data not shown). In FADD-DN BJAB cells TRAIL receptors were downregulated upon TRAIL overexpression but cells did not grow out, since these cells are already resistant towards TRAIL and therefore have no selection advantage under constant TRAIL exposure. These data strongly suggest that specific resistance towards TRAILinduced apoptosis is induced by lentiviral TRAIL overexpression involving blockade of caspase-8 and loss of TRAIL receptor surface expression, apparently depending on the amount of TRAIL expression.

\section{TRAIL receptor protein is retained within the cells, and DISC formation is abrogated}

Since TRAIL-R1 and TRAIL-R2 mRNA was still detectable in resistant cells (Figure $5 \mathrm{a}$ ), we analyzed intracellular protein expression by FACS analysis of permeabilized BJAB cells (Figure 5b). Despite fixation, some GFP was lost due to permeabilization. Also, the TRAIL-R1 antibody did not work with fixed samples as good as with unfixed cells. We found expression of TRAIL-R2, at a lower level than in GFPtransduced control cells, but no expression of TRAIL-R1 in TRAIL-transduced cells. These findings indicate that transla- 
a

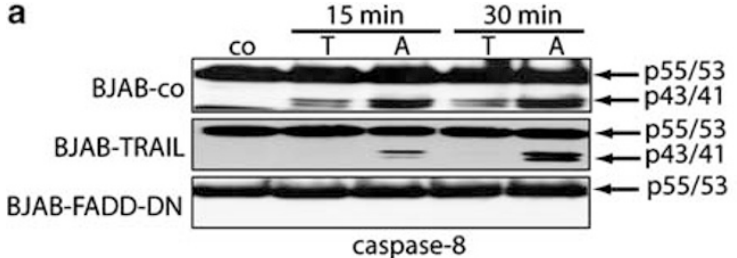

b

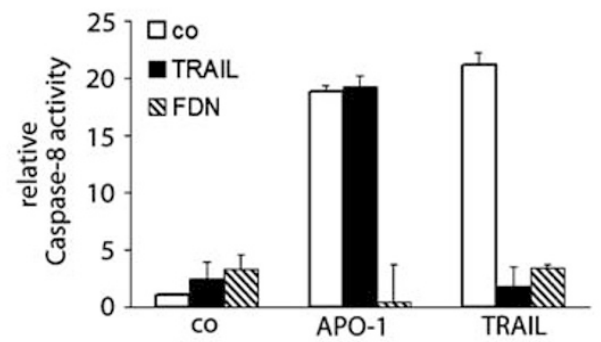

C

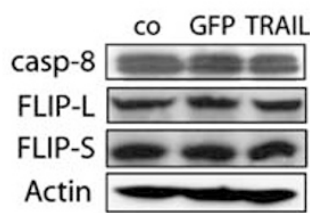

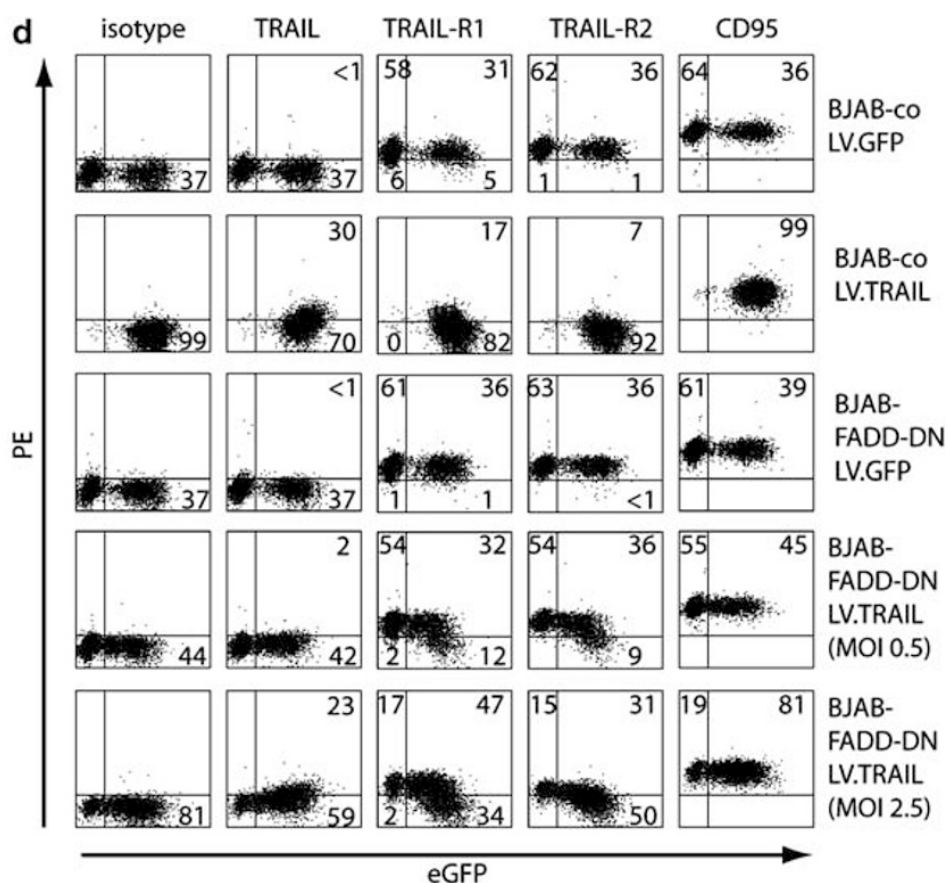

Figure 4 Lack of caspase-8 activation and down-regulation of TRAIL-R1 and -R2 cell surface expression in resistant cells. (a) BJAB cells 30 days after transduction were stimulated for 15 and 30 min with anti-APO-1 (A, $500 \mathrm{ng} / \mathrm{ml}$ ) or TRAIL (T, $500 \mathrm{ng} / \mathrm{ml}$ ) and extracts were analyzed for caspase-8 cleavage by Western blotting. (b) BJAB cells were stimulated for $6 \mathrm{~h}$ as indicated above and caspase-8 activity was measured by IETD-AFC cleavage assay. (c) Lysates from parental BJAB cells (co) or BJAB cells transduced with LV.GFP (GFP) or LV-TRAIL 30 days after transduction were examined by Western blotting, using anti-c-FLIP mAb NF6 and anti-FLICE mAb C15. (d) FACS analysis of TRAIL, TRAIL-R1, TRAIL-R2 and CD95 cell surface expression 30 days after transduction. BJAB wt cells were transduced with LV.GFP or LV.TRAIL at MOI 0.5, BJAB FADD-DN transduced were transduced with LV.GFP or LV.TRAIL at MOI 0.5 or with LV.TRAIL at MOI 2.5. Cells were stained with the indicated antibodies and a PE-conjugated secondary antibody. Numbers given in the dot plots are the percentage of cells in the respective quadrants (no percentage given: $<1)$

tion, transport or stability of protein rather than a loss of transcription of TRAIL-R2 might have been affected. Since the antibodies used for TRAIL receptor staining functionally block receptor activation by the ligand, ${ }^{11}$ we investigated whether receptor-bound TRAIL might vice versa block or diminish staining of TRAIL receptors. We pre-incubated BJAB cells with recombinant TRAIL prior to staining and could detect bound TRAIL on the cell surface by FACS analysis. Surface staining with anti-TRAIL receptor antibodies was blocked by this treatment in a dose-dependent manner (Figure 5c). Only the TRAIL-R1 signal could be completely abrogated, while TRAIL-R2 staining was only partially impaired. To further investigate the levels of intracellularly retained TRAIL-R1 and TRAIL-R2 protein, we used coimmunoprecipitation experiments (Figure $5 \mathrm{~d}$ ) since the available polyclonal TRAIL-R1 and TRAIL-R2 antibodies gave strong unspecific signals when using directly cell extracts analyzed by Western blotting. To detect intracellular TRAIL-R1 and TRAIL-R2 protein and to test for presence or absence of a functional DISC in resistant cells, we used LV.GFP- and LV.GFPTRAIL-transduced BJAB cells. The LV.GFPTRAIL vector was exclusively constructed for this particular experiment since attempts to use a fulllength membrane-bound human TRAIL variant containing an $\mathrm{N}$-terminal intracellular FLAG-tag failed. Despite protein expression detectable in Western blot analysis, surface expression of this construct could not be detected in 293T cells (Supplementary Figure S1) or BJAB cells (data not shown). In control experiments, we ensured that the proper- ties of the GFPTRAIL fusion protein with respect to apoptosis and resistance induction were similar to those of full-length TRAIL coexpressed with GFP by LV.TRAIL (data not shown). For precipitation of the TRAIL DISC or of TRAIL receptors from lysates, we used FLAG-tagged TRAIL together with antiFLAG M2 antibody. ${ }^{11}$ Upon TRAIL stimulation for $30 \mathrm{~min}$, a TRAIL DISC containing TRAIL-R1, TRAIL-R2, and caspase-8 formed in BJAB-control and BJAB-GFP cells (Figure $4 d$ ). In BJAB-GFPTRAIL cells no detectable TRAIL receptors and only small amounts of unprocessed caspase-8 could be precipitated. By co-precipitation with FLAG-TRAIL, large amounts of TRAIL-R1 and TRAIL-R2 could be detected in lysates of control and LV.GFP-transduced cells, but not from BJAB-GFPTRAIL cells. GFPTRAIL seemed to have competed with FLAG-TRAIL for TRAIL-R binding and inhibited precipitation with FLAG-TRAIL, since TRAIL-R1 and TRAILR2 were co-precipitated from lysates of BJAB-GFPTRAIL cells, using anti-GFP antibody to precipitate GFPTRAIL. GFPTRAIL was detected by Western blotting using antiTRAIL antibody only after immunoprecipitation and not in lysates, despite high protein levels detected by FACS analysis (data not shown). These findings indicate that TRAIL-R1 and TRAIL-R2 proteins are still synthesized in resistant TRAILoverexpressing cells and that they are able to interact with TRAIL but are present at lower levels. These results also confirm the absence of functional TRAIL death receptors from the cell surface of resistant cells. TRAIL-R1 and TRAIL-R2 protein are present within the cells but are not or only weakly 


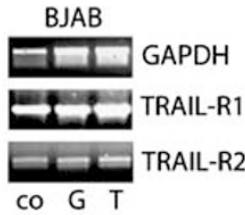

P693

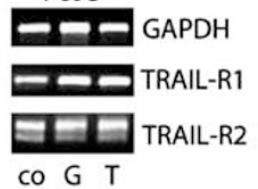

co G T b

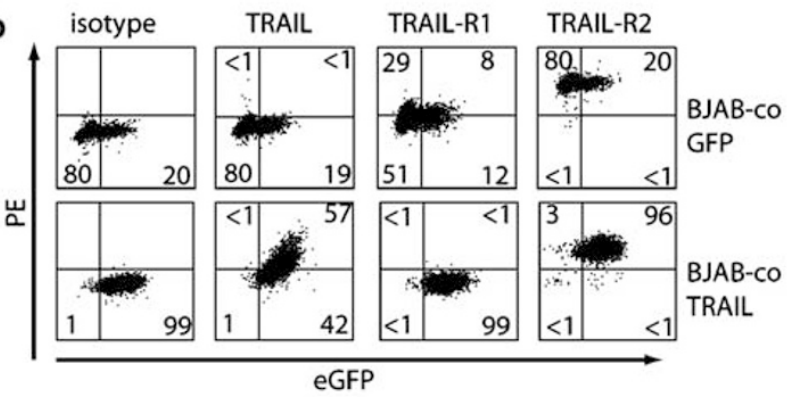

d

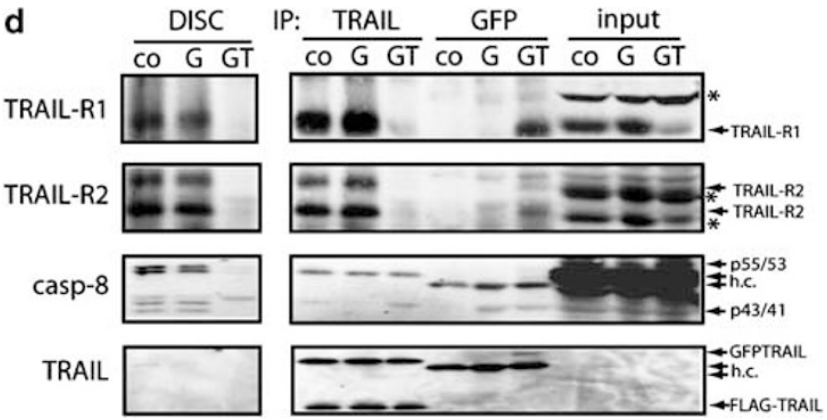

Figure 5 Intracellular retention of TRAIL-R1 and -R2 protein and disturbed DISC formation in resistant cells (a) TRAIL Receptor 1 and 2 mRNA is detectable in resistant cells. RT-PCR analysis of TRAIL Receptor expression (28 cycles) and GAPDH ( 23 cycles) was performed on RNA from BJAB and P693 cells 30 days after transduction with LV.GFP or LV.TRAIL. (b) At 30 days after transduction, expression of TRAIL, TRAIL-R1 and -R2 was measured by intracellular staining and FACS analysis. Cells were fixed, permeabilized, and stained with the indicated antibodies and a PE-conjugated secondary antibody. Numbers given in the dot plots are the percentage of cells in the respective quadrants (no percentage given when $<1$ ). (c) TRAIL-R1 and -R2 cell surface expression was analyzed by FACS in BJAB cells preincubated with FLAG-TRAIL for $30 \mathrm{~min}$ Bound TRAIL was detected by staining with anti-FLAG M2 antibody. (d) For DISC analysis, BJAB cells were stimulated with FLAG-TRAIL and M2 for $30 \mathrm{~min}$ at $37^{\circ} \mathrm{C}$. For immunoprecipitation, cell lysates were incubated with FLAG-TRAIL and M2, or anti-eGFP and Protein G-Agarose overnight. Eluted proteins were resolved by SDS-PAGE and Western blotting. h.c.: heavy chain; Asterisks: unspecific bands

detectable using monoclonal antibodies, which can be blocked by bound TRAIL. This suggests that intracellular interaction of the ligand with the receptors prevents antibody binding by competition, induces intracellular retention of TRAIL-R1 and TRAIL-R2 and causes resistance towards TRAIL.

\section{Intracellularly retained TRAIL-R2 protein colocalizes with GFPTRAIL in the ER/golgi}

To detect the localization of intracellular TRAIL-R2 protein, we performed immunofluorescence analysis and confocal microscopy of LV.GFP- and LV.GFPTRAIL-transduced BJAB (data not shown) and $P 693$ cells (Figure 6). A fluorescent derivative of Brefeldin A (BFA), BFA-BODIPY $559^{25}$ was used to stain ER and golgi-apparatus (blue). GFP was ubiquitously expressed and did not specifically localize to any compartment except for some nuclear accumulation. GFPTRAIL localized to the plasma membrane and clustered intracellularly in the area of the ER/golgi apparatus (blue-green colour in the overlay picture). TRAIL-R2 (red) localized both to the plasma membrane (white arrows in the overlay picture) and to the ER/golgi (pink colour in the overlay picture) in LV.GFPtransduced cells. In LV.GFPTRAIL-transduced cells, TRAILR2-staining was weak and detectable only intracellularly, but not on the plasma membrane. It largely overlapped with GFPTRAIL within the ER/golgi apparatus (yellow staining in the overlay picture), but a small amount of TRAIL-R2 protein also colocalized with ER/golgi only (pink colour in the overlay, yellow arrows). These data confirm retention of TRAIL-R2 within the ER/golgi apparatus and show colocalization of TRAIL-R2 and GFPTRAIL.

\section{Resensitization of TRAIL-resistant cells}

Finally, to corroborate the assumed mechanism involved in resistance induction upon TRAIL overexpression, we attempted to resensitize the resistant BJAB cells. The use of tunicamycin, a glycosylation inhibitor and inducer of ER stress and apoptosis ${ }^{26}$ which has been reported to resensitize TRAIL-resistant cells with intracellular TRAIL receptor retention, ${ }^{15}$ was not effective in our system (Supplementary Figure 2). We observed a slightly higher toxicity on Tunicamycin in BJAB-TRAIL cells compared to BJAB-GFP cells at early timepoints, possibly due to a predisposition towards ER stress by the intracellular protein interaction. However, we were quite successful using RNAi oligonucleotides towards TRAIL. Knock down of TRAIL overexpression upon transient transfection of a TRAIL-specific siRNA, but not of an unspecific control siRNA resulted in a decrease of TRAIL expression in BJAB-TRAIL and an increase in TRAIL-R1 and TRAIL-R2 surface expression (Figure 7a). This did not occur in BJABGFP cells treated similarly, with the exception of a slight increase of TRAIL-R2 expression. However, a complete resensitization could not be achieved, since the TRAIL knock down was not complete. This is indicated by the TRAIL mean fluorescence intensity (MFI) obtained in BJAB-TRAIL cells, which decreased from 14 (control-siRNA) to 9 (TRAILsiRNA). In comparison, the TRAIL MFI of BJAB-GFP cells remained at 5. Similarly, the TRAIL-R1 and TRAIL-R2 surface expression levels of the resistant cells were increased upon TRAIL siRNA transfection, but did not reach the wild-type levels. Therefore, the TRAIL knock down only partially resensitized the resistant cells towards TRAIL-induced apoptosis, but had no effect on the TRAIL sensitivity of BJAB-GFP cells, as expected (Figure 7b). These data demonstrate that the TRAIL overexpression itself is respon- 

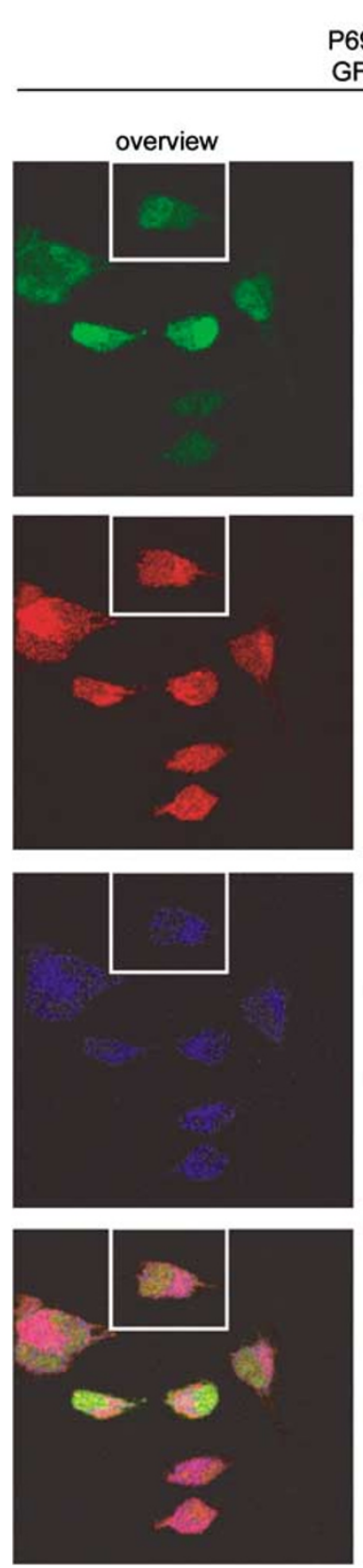

P693-

GFP:
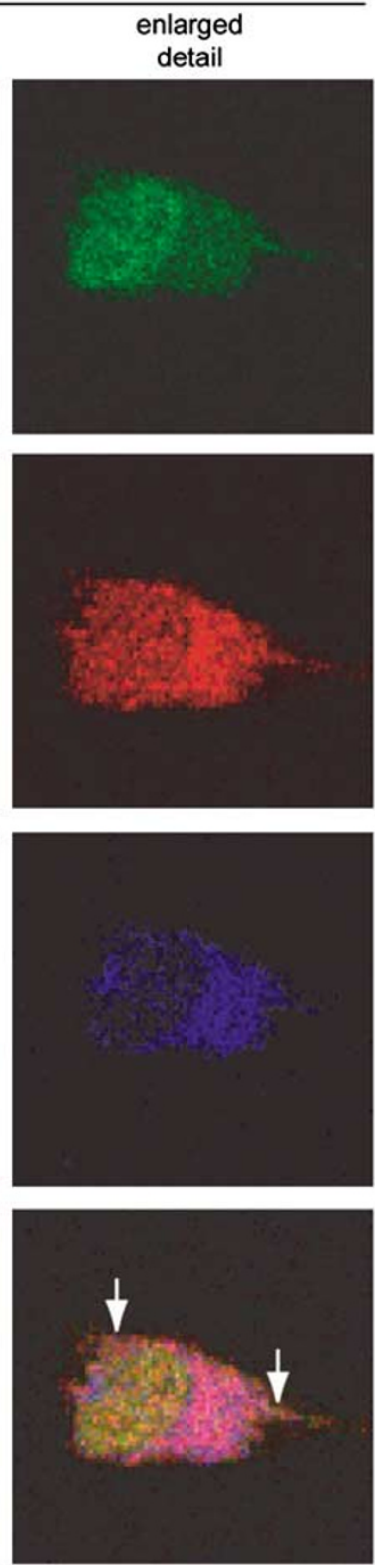

Figure 6 Intracellular retained TRAIL receptor 2 colocalizes with GFPTRAIL in the ER/golgi complex. P693 cells were transduced with LV.GFP or LV.GFPTRAIL (green) and cultured for 10 days. Cells were seeded onto glass coverslips, incubated with the ER/golgi marker (blue) BrefeldinA-BODIPY (BFA-B, $200 \mathrm{ng} / \mathrm{ml}$ ) for $10 \mathrm{~min}$, fixed, and stained using anti-TRAIL-R2 and anti-mouse-IgG-AlexaFluor 647 (red). The enlarged detail picture corresponds to the white box in the overview picture

sible for the retention of the receptors and the induction of resistance.

\section{Discussion}

TRAIL signaling has been studied extensively, as well as factors influencing sensitivity or resistance towards this molecule. Applying this knowledge to therapeutic manipulation of apoptosis is promising, especially for the treatment of human malignant disease. ${ }^{12}$ Here, we describe a novel

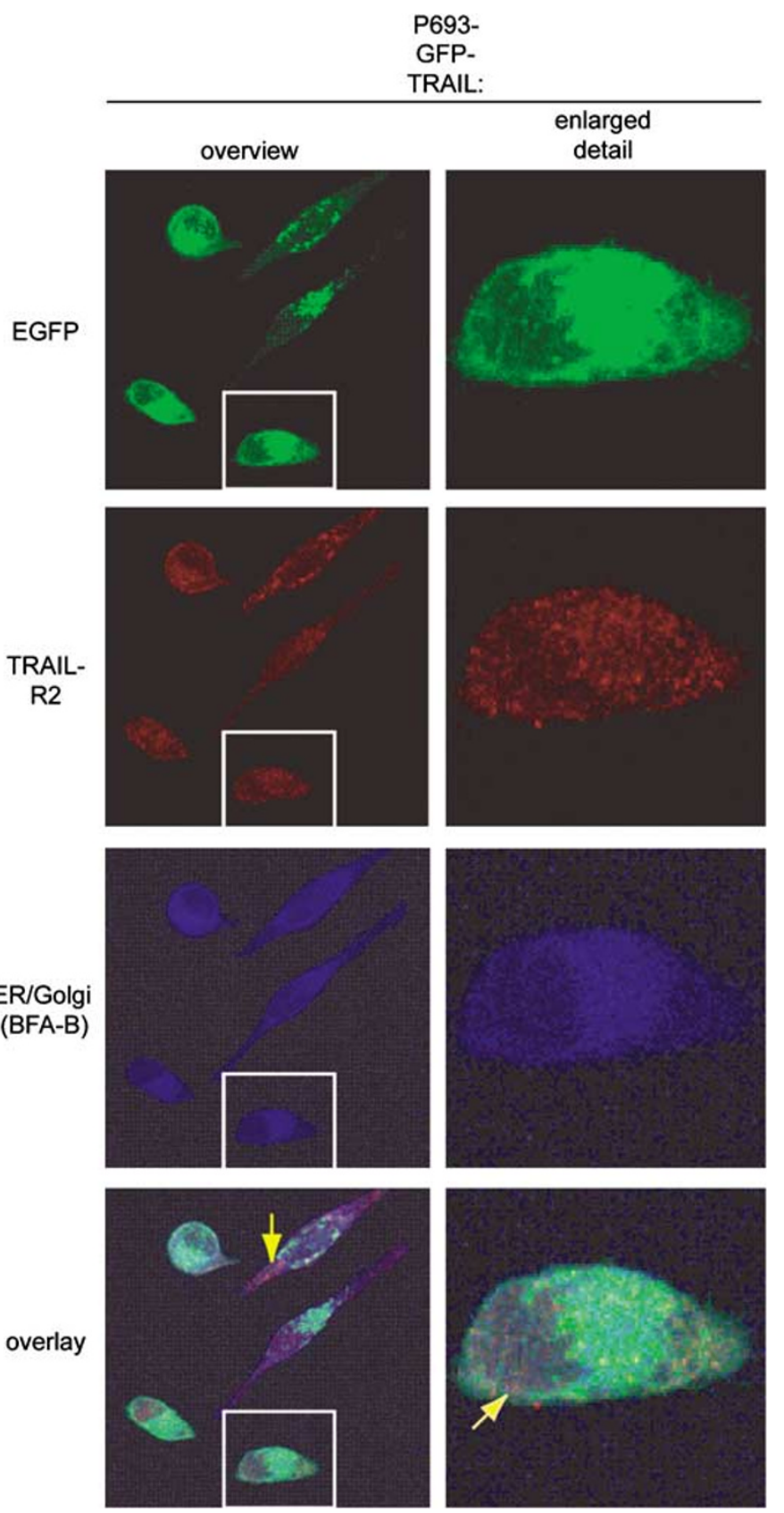

P693- 

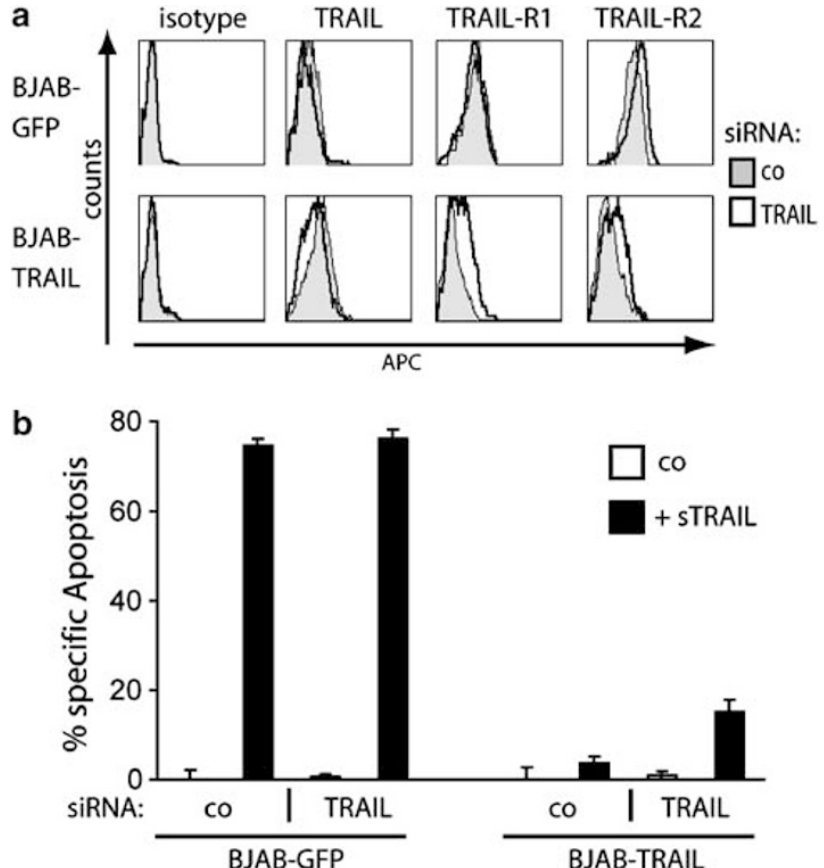

Figure 7 TRAIL siRNA partially restores TRAIL receptor 1 and 2 expression and TRAIL sensitivity. (a) BJAB cells transduced with LV.GFP (BJAB-GFP) or LV-TRAIL (BJAB-TRAIL) were transfected with a control siRNA (co, filled histograms) or a TRAIL-specific siRNA (TRAIL, open histograms) together with a Cy3-labeled control siRNA. At $72 \mathrm{~h}$ post-transfection, surface expression was analyzed by FACS using unspecific (isotype), TRAIL-, TRAIL-R1- and TRAIL-R2specific primary and APC-conjugated secondary antibodies, and 7-AAD. Analysis included only viable transfected cells $\left(\mathrm{Cy} 3^{+} / 7-\mathrm{AAD}^{-}\right)$. (b) Cells were transfected as indicated above and either left untreated (co) or stimulated after $48 \mathrm{~h}$ for $24 \mathrm{~h}$ with $100 \mathrm{ng} / \mathrm{ml}$ recombinant TRAIL (TRAIL). Apoptosis was measured by staining with Annexin V-biotin and Streptavidin-APC. Analysis included only viable transfected cells $\left(\mathrm{Cy}^{+}{ }^{+} / 7-\mathrm{AAD}^{-}\right)$

associated with viral particles to be responsible for transduction-independent cell death, consistent with recent findings demonstrating that retroviral particles are able to transfer proteins present in packaging cells. ${ }^{19,30}$ In this context, it may be interesting that AZT has been reported to sensitize for TRAIL-mediated apoptosis in certain cell types. ${ }^{31}$ Thus, the transduction-independent cell death may be overestimated in this particular assay.

The development of apoptosis resistance occurred as early as $96 \mathrm{~h}$ after transduction and was specific towards TRAIL, a phenomenon hitherto not described. Resistance was caused by intracellular retention of TRAIL receptors, preventing DISC formation and caspase-8 activation upon TRAIL stimulation. Since only TRAIL signaling was affected, the cells remained sensitive to induction of apoptosis by other stimuli such as CD95L or cisplatin. This finding corresponds to our recent results using stable transfection of a Tet-inducible mammalian expression plasmid for TRAIL. ${ }^{13}$ Quite similarly, the tumor cells used in this study also developed specific resistance towards TRAIL-induced apoptosis suggesting that the underlying mechanism may be more common. One might speculate, that it might be a naturally occurring way by which TRAIL-overexpressing cells protect themselves from death by intracellular retention of the respective death receptors. In line with our assumption, TRAIL receptor expression and TRAIL sensitivity could be partially restored by RNA interference against TRAIL. We could, however, not achieve full TRAIL knock down and resensitization by using RNAi oligonucleotides, presumably due to the high TRAIL mRNA levels produced by the CMV promoter of the lentiviral TRAIL construct. These observations, together with the fast development of resistance only in transduced cells, the intracellular retention of TRAIL receptors occurring also in already resistant BJAB-FADD-DN cells, and the dependence on the amount of TRAIL surface expression, clearly negate the possibility of outgrowth of just a few clones with pre-existing loss of receptor expression, but rather support our proposed mechanism of outgrowth of the whole transduced bulk population and caused directly by TRAIL overexpression. TRAIL resistance has been attributed to a number of alterations in death signaling, including overexpression of 'decoy' receptors, ${ }^{32} \mathrm{FLIP},{ }^{33} \mathrm{Bcl}-2,{ }^{34}$ IAPs, ${ }^{35,36}$ and loss of caspase-8 expression. ${ }^{37}$ Although there is no clear correlation of expression patterns of decoy receptors and TRAIL sensitivity, their precise role in TRAIL signaling remains unclear. ${ }^{10}$ Furthermore, NF- $\kappa$ B activation by TRAIL receptors has been previously described and implicated in TRAILinduced proliferation of TRAIL-resistant cells ${ }^{14}$ and in induction of pro-inflammatory cytokines. ${ }^{38}$ Induction of resistance by TRAIL gene therapy has not been investigated extensively although one study ${ }^{16}$ describes the upregulation of $\mathrm{Bcl}-\mathrm{x}_{\mathrm{L}}$ as the main resistance factor towards Ad TRAIL expression. We found a resistance mechanism that works via the specific inhibition of TRAIL-induced apoptosis at the level of TRAILDISC-associated caspase-8 activation. The alternative above-mentioned mechanisms may be excluded in our system, since only TRAIL signaling was affected. CD95 and TRAIL pathways rely on the same molecules for receptor proximal events in apoptosis induction. ${ }^{24}$ Changes in other effector molecules would influence death signaling downstream of caspase-8 or even confer resistance to a broad range of apoptotic stimuli. However, CD95-mediated and DNA damage-induced apoptosis was unaffected in TRAILresistant cells. In a recent study, TRAIL resistance due to intracellular retention of TRAIL receptors was reported. ${ }^{15}$ Despite similarities to our data, there are fundamental differences. In our system, resistance occurred within days upon TRAIL expression, in bulk cultures and only in TRAIL transduced cells, while Jin et al. performed prolonged selection of single clones. In addition, the retention of receptors in cells already resistant to lentiviral TRAIL-induced apoptosis due defective death receptor signaling excludes the outgrowth under selection pressure of clones with disturbed TRAIL death receptor transport and rather points towards the direct involvement of TRAIL overexpression. Our data strongly suggest induction of TRAIL-specific resistance by intracellular interaction of overexpressed TRAIL and endogenous TRAIL death receptors, leading to retention of the receptors within the ER/golgi complex. This retention mechanism resembles the phenomenon of retroviral superinfection interference, ${ }^{39}$ which is caused by intracellular interaction of the endogenous receptor and a virally overexpressed ligand, the envelope protein. Ultimately, this leads to loss of surface expression of the receptor, preventing further infection with the same type of virus. Despite 
intracellular colocalization and very likely also interaction of TRAIL and TRAIL-R2, this did not result in detectable signaling by TRAIL-R2. Caspase-8 was not associated with TRAIL-R2 protein precipitated from GFPTRAIL overexpressing cells. Possibly, TRAIL death receptor signaling requires additional factors present only at the plasma membrane, but not at the membranes of intracellular compartments, or is otherwise dependent on the surrounding cellular compartment and can only be started at the plasma membrane. Receptor internalization has been observed for CD95 and TNF-receptor and suggested to be important for signaling. ${ }^{40,41}$ Although the role of receptor internalization in signaling remains controversial, this points to the importance of the site of signaling initiation within TNF-receptor family members. Autocrine apoptosis induction by TRAIL has been reported in 'helpless' CD8 + T-cells. ${ }^{42}$ In this case, s TRAIL mediated the observed AICD. The finding that expression of membrane bound TRAIL in cells which normally do not express TRAIL can cause TRAIL resistance thus demonstrates that TRAIL effector function, especially in an autocrine manner, might be regulated at multiple levels. These include protein expression, protein sorting, cleavage of the protein to the $s$ form and exocytosis of stored s TRAIL. Further analysis of these processes might provide valuable insights into the function of the TRAIL system and its biological role.

In line with our data, intracellular colocalization of the ligand with its receptors was shown upon adenoviral transfer of a GFP-tagged CD95L. ${ }^{43}$ In this case, no resistance towards CD95-mediated apoptosis was found since intracellular CD95 triggering was reported. However, alternative effectors might be involved in this case, since functional participation of molecules involved downstream in CD95 signaling was not reported. Also, this might represent fundamental differences of TRAIL and CD95 signaling with respect to possible sites of signaling initiation. Differences in experimental parameters and expression kinetics between the system, we describe here and published data on TRAIL gene transfer are also important for the observation of resistance. Gene expression by adenoviral vectors happens within hours after transduction. In contrast, lentiviral vectors may take up to $24 \mathrm{~h}$ for gene expression $^{44}$ due to reverse transcription and integration. Upon transduction of the majority of cells at high multiplicity of infection (MOI), the fast kinetics and high expression levels achieved by adenoviral vectors may lead to immense cell death shortly after transduction, ${ }^{2}$ and thereby prevent the detection of resistance. In contrast, the lentiviral system used in this study may have allowed for the outgrowth of resistant cells due to slower expression kinetics and stable TRAILexpression.

TRAIL gene transfer into tumor cells is currently discussed as a promising anti-tumor approach. Our findings prompt for reconsideration of this approach as monotherapy. Since combination with chemotherapy has been shown to greatly enhance TRAIL gene therapy efficacy, ${ }^{29}$ application of this combination in a human therapy setting appears to be far more promising. We would like to point out that our findings may also lead to the development of more effective, combined gene therapy approaches, for example, using TRAIL in combination with a suicide gene, such as hsv-tk or Escherichia coli cytosine deaminase: viral expression of TRAIL might kill the majority of tumor cells, while only transduced cells become resistant and grow out. The heavily enriched transduced population of a tumor might subsequently be killed by prodrug application, leading to much more efficient tumor cell eradication than either of the gene therapeutic approaches alone.

\section{Materials and Methods}

\section{Cell culture}

Cell culture media (PAA, Pasching, Austria) was supplemented with $10 \%$ heat-inactivated FCS (Sigma, Deisenhofen, Germany), 2 mM L-glutamine (PAA), $10 \mathrm{mM}$ HEPES (PAA) and $2.5 \mu \mathrm{g} / \mathrm{ml}$ Plasmocin (InvivoGen, San Diego, USA). For virus production, DMEM with $4 \mathrm{mM}$ L-glutamine was used. Cells were cultured at $37^{\circ} \mathrm{C}$ and $5 \% \mathrm{CO}_{2}$. BJAB control (co) cells and BJAB cells expressing dominant negative FADD (FADD-DN), ${ }^{13,45} \mathrm{BL}$ 60 cells, ${ }^{24}$ Jurkat JA3 wt, and caspase-8 deficient Jurkat JA3 cells ${ }^{46}$ were cultured in complete RPMI. P693 non-small cell lung cancer cells, ${ }^{47}$ MIAPACA pancreatic carcinoma cells (kindly provided by $\mathrm{H}$ Friess), P5 cervix carcinoma cells, ${ }^{48}$ and HEK $293 \mathrm{~T}^{49}$ cells were cultured in complete DMEM.

\section{Antibodies and reagents}

Antibodies used were mouse monoclonal anti-TRAIL 2E5 (FACS) and HS501 (Western blotting), anti-TRAIL-R1, -R2, -R3 and -R4, clones HS 101, HS 201, HS 301, HS 401 (FACS) (all from Alexis, Grünberg, Germany), anti-Actin (C-4) (ICN, Eschwege, Germany), anti-CD3CyChrome (Becton Dickinson, Heidelberg, Germany), anti-eGFP (JL8) (Clontech, Heidelberg, Germany), anti-FLAG M2, IgG1 isotype control (MOPC 21) (both from Sigma), anti-HIV gag p24, ${ }^{50}$ anti-APO-1, antiFLICE $\mathrm{C} 15$ and anti-FLIP NF6, ${ }^{51,52}$ rabbit polyclonal anti-DR4 (CT) (Western blotting) (Alexis), anti-DR5 (Western blotting) (Sigma), antimouse-lgG-R-PE (Caltag, Burlingame, CA, USA), anti-mouse-Ig-HRP (SantaCruz, Heidelberg, Germany), anti-rabbit-Ig-HRP (Southern Biotechnologies, Birmingham, AL, USA), anti-mouse-IgG-AlexaFluor647 and Brefeldin A-BODIPY (Molecular Probes, Eugene, OR, USA). All other chemicals were from Sigma or Carl Roth (Karlsruhe, Germany).

\section{Transfection, virus preparation and titer determination}

Vector stocks were produced according to previously described protocols ${ }^{53,54}$ with modifications. $1.8 \times 10^{7} 293 \mathrm{~T}$ cells in T150 flasks were transfected with $20 \mu \mathrm{g}$ transfer vector, $14 \mu \mathrm{g}$ pCMVÄR89. 1 helper plasmid and $7 \mu \mathrm{g}$ pMD.2 envelope plasmid by $\mathrm{CaPO}_{4}$ precipitation. The supernatant was collected $24 \mathrm{~h}$ and $48 \mathrm{~h}$ after transfection, cleared by filtration $(0.45 \mu \mathrm{m}$, Millipore, Bedford, MA, USA) and concentrated by ultracentrifugation (140 min, $20000 \mathrm{rpm}$, SW28 rotor). The pellet was resuspended in $\mathrm{PBS} / 0.1 \% \mathrm{BSA}$, stored at $-70^{\circ} \mathrm{C}$, and titered by infection of $293 \mathrm{~T}$ cells with serial dilutions and subsequent FACS analysis (FACSCalibur, Becton Dickinson). Titers achieved ranged from $5 \times 10^{8}$ $4 \times 10^{9}$ Infectious Units (IU)/ml.

\section{Transduction of cultured cells}

Cells were seeded in six-well plates at $2 \times 10^{5}-2 \times 10^{6}$ cells per well in $2-$ $5 \mathrm{ml}$ complete medium containing $4 \mu \mathrm{g} / \mathrm{ml}$ Polybrene and virus was added. 
AZT was used at $5 \mu \mathrm{g} / \mathrm{ml}$. The plates were centrifuged at $1200 \mathrm{rpm}, 32^{\circ} \mathrm{C}$ for $1 \mathrm{~h}$ and incubated at $37^{\circ} \mathrm{C}$. Medium was changed after $6-16 \mathrm{~h}$.

\section{Stimulation of cells}

Solutions of cisplatin in DMSO, FLAG-TRAIL, LZ-TRAIL, ${ }^{5}$ and antiAPO $-1^{55}$ in PBS were used for stimulation at concentrations and times indicated.

\section{Plasmid construction and preparation}

All lentivirus (LV) plasmids were derived from the plasmid pWPTS-eGFP (kind gift from D Trono, Geneva) and contained HIV-1 derived 5' $5^{\prime}$ LTR, packaging signal, RRE (Rev responsive element), CPPT/CTS and SIN $3^{\prime}$ LTR, and the WPRE (Woodchuck hepatitis virus posttranscriptional regulatory element) element. ${ }^{18,56}$ LV.GFP was constructed by replacing the eGFP sequence and the EF1á promoter in pWPTS-eGFP with the CMV-IRES-eGFP cassette from pIRES2-eGFP (Clontech, Heidelberg, Germany). LV.TRAIL was constructed by inserting a full-length human TRAIL CDNA ${ }^{13}$ in between the CMV promoter and the IRES element. LV.GFPTRAIL was constructed by replacing the IRES-GFP cassette from LV.GFP with the GFP-TRAIL fusion protein CDNA ${ }^{57}$ kindly provided by $\mathrm{Dr}$ B Fang, Houston, USA. Plasmid DNA was prepared using GenElute kits (Sigma), precipitated and dissolved in sterile water.

\section{Measurement of apoptosis and flow cytometry}

Apoptosis was measured by flow cytometry using the Nicoletti method, ${ }^{58}$ by staining with AnnexinV-PE or AnnexinV-Biotin and Streptavidin-APC (Becton Dickinson) according to the manufacturer's instructions, or by recording the FSC/SSC profile of PI-negative cells. Experiments were performed at least three times in triplicate and values given are the mean of triplicates \pm S.D. For antibody stainings, primary antibody was used at $5 \mu \mathrm{g} / \mathrm{ml}$ and goat-anti-mouse-lgG-R-PE at 1:50 dilution. For intracellular stainings, the BD Intrastain kit (Becton Dickinson) was used according to the manufacturer's instructions. In all, $2 \times 10^{5}$ cells per sample were used and at least $1 \times 10^{4}$ cells were measured (FACScalibur and CellQuest software, Becton Dickinson).

\section{MTT assay}

In all, $2 \times 10^{4}$ cells in $100 \mu$ l were plated in 96-well plates and stimulated. $10 \mu \mathrm{l}(10 \mathrm{mg} / \mathrm{ml}$ in PBS) of MTT (Sigma) were added and cells were further incubated for $4 \mathrm{~h}$. $100 \mu \mathrm{l}$ Isopropanol/ $0.04 \mathrm{~N} \mathrm{HCl}$ were added, incubated at $37^{\circ} \mathrm{C}$ for $5 \mathrm{~min}$ and $1 \mathrm{~h}$ at room temperature on a shaker. The optical density $(550 \mathrm{~nm})$ of wells was measured with an ELISA reader.

\section{Preparation of cell lysates, immunoprecipitation and Western blot}

Cell lysis and immunoprecipitation was carried out as described. ${ }^{24} 2 \mu \mathrm{g}$ of anti-eGFP- or anti-FLAG-M2-antibody and $1 \mu \mathrm{g}$ FLAG-TRAIL were used. Eluted proteins or cell lysates were separated on $12 \%$ polyacrylamide gels, and transferred to nitrocellulose membranes (Amersham Biosciences, Freiburg, Germany) by semidry electroblotting. The membranes were blocked in $5 \%$ skim milk in PBS $/ 0.02 \%$ Tween 20 , incubated for $2 \mathrm{~h}$ at room temperature with the first antibody, $30 \mathrm{~min}$ with the second antibody and developed using enhanced chemoluminescence (Perkin Elmer, Rodgau, Germany).

\section{Caspase-8 assay}

For determination of caspase-8 activity by IETD-AFC cleavage, the ApoAlert kit (Clontech) was used according to the manufacturer's instructions. AFC fluorescence was measured using a Victor fluorometer (Perkin Elmer, Rodgau, Germany).

\section{RT-PCR}

Total RNA was harvested (RNeasy kit, Qiagen, Hilden, Germany), converted to CDNA and PCR was performed as previously described. ${ }^{48}$ Primers were TRAIL receptor 1: gttgttgcatctcatcaggttgt and gaggcgttccgtc caggtttgttg, yielding a $490 \mathrm{bp}$ fragment and spanning exon-intron boundaries. TRAIL receptor 2: tggccccacaacaaaagaggtc and cagccc caggtcgttgtgagc, yielding a 603 and $520 \mathrm{bp}$ fragments for the two described transcript variants and spanning exon-intron boundaries. GAPDH: ccacccatggcaaattctccatggca and tctagacggcaggtcaggtccacc (600 bp).

\section{Immunofluorescence analysis}

Cells were grown on $5 \mathrm{~mm}$ diameter coverslips, fixed with $4 \%$ paraformaldehyde, washed with PBS, quenched with $50 \mathrm{mM} \mathrm{NH}_{4} \mathrm{Cl}$ in PBS, washed and permeabilized with $0.1 \%$ Saponin $/ 10 \%$ FCS in PBS. Slides were incubated with primary antibody for $1 \mathrm{~h}$, washed and incubated with secondary antibody for $1 \mathrm{~h}$, washed again, mounted in Fluoromount G (Southern Biotech, Birmingham, Al, USA) and examined by confocal microscopy (Leica TSL, Leica Microsystems, Bensheim, Germany).

\section{Transient SiRNA transfection}

SmartPool ${ }^{\circledR}$ siRNA directed against TRAIL or smartPool ${ }^{\circledR}$ control siRNA (Dharmacon, Lafayette, CO, USA) were co-transfected at a ratio of 4: 1with a Cy3-labeled RISC-free ${ }^{\circledR}$ (Dharmacon) RNA into BJAB cells using the AMAXA nucleofector kit V (Amaxa, Cologne, Germany). 48-72 h post-transfection, cells were used for the respective assays, and only viable $\left(7-\mathrm{AAD}^{-}\right)$transfected $\left(\mathrm{Cy} 3^{+}\right)$were analyzed.

\section{Acknowledgements}

We thank A Hong, SC Fas, CR Frey for critical discussion of the manuscript, E Klimczak, M Roth, J Gabler, M Mildenberger, K Becker and $Y$ Doerflinger for excellent technical assistance, D Trono for providing lentiviral plasmids and Dr. B Fang for GFPTRAIL cDNA. The anti-HIV-1 p24 antibody (183-H12-5C) was obtained through the AIDS Research and Reference Program, Division of AIDS, NIAID, NIH (Dr. B Chesebro).

\section{References}

1. Mohr A, Henderson G, Dudus L, Herr I, Kuerschner T, Debatin KM, Weiher H, Fisher KJ, Zwacka RM (2004) AAV-encoded expression of TRAIL in experimental human colorectal cancer leads to tumor regression. Gene Therapy 11: 534-543.

2. Griffith TS, Anderson RD, Davidson BL, Williams RD, Ratliff TL (2000) Adenoviral-mediated transfer of the TNF-related apoptosis-inducing ligand/ Apo-2 ligand gene induces tumor cell apoptosis. J. Immunol. 165: 2886-2894.

3. Griffith TS, Broghammer EL (2001) Suppression of tumor growth following intralesional therapy with TRAIL recombinant adenovirus. Mol. Ther. 4: 257-266. 
4. Ashkenazi A, Pai RC, Fong S, Leung S, Lawrence DA, Marsters SA, Blackie C, Chang L, McMurtrey AE, Hebert A, DeForge L, Koumenis IL, Lewis D, Harris L, Bussiere J, Koeppen H, Shahrokh Z, Schwall RH (1999) Safety and antitumor activity of recombinant soluble Apo2 ligand. J. Clin. Invest. 104: 155-162.

5. Walczak H, Miller RE, Ariail K, Gliniak B, Griffith TS, Kubin M, Chin W, Jones J, Woodward A, Le T, Smith C, Smolak P, Goodwin RG, Rauch CT, Schuh JC, Lynch DH (1999) Tumoricidal activity of tumor necrosis factor-related apoptosis-inducing ligand in vivo. Nat. Med. 5: 157-163.

6. Roth W, Isenmann S, Naumann U, Kugler S, Bahr M, Dichgans J, Ashkenazi A, Weller M (1999) Locoregional Apo2L/TRAIL eradicates intracranial human malignant glioma xenografts in athymic mice in the absence of neurotoxicity. Biochem. Biophys. Res. Commun. 265: 479-483.

7. Gliniak B, Le T (1999) Tumor necrosis factor-related apoptosis-inducing ligand's antitumor activity in vivo is enhanced by the chemotherapeutic agent CPT-11. Cancer Res. 59: 6153-6158.

8. Jo M, Kim TH, Seol DW, Esplen JE, Dorko K, Billiar TR, Strom SC (2000) Apoptosis induced in normal human hepatocytes by tumor necrosis factorrelated apoptosis-inducing ligand. Nat. Med. 6: 564-567.

9. Dorr J, Bechmann I, Waiczies S, Aktas O, Walczak H, Krammer PH, Nitsch R, Zipp $F$ (2002) Lack of tumor necrosis factor-related apoptosis-inducing ligand but presence of its receptors in the human brain. J. Neurosci. 22: RC209.

10. LeBlanc HN, Ashkenazi A (2003) Apo2L/TRAIL and its death and decoy receptors. Cell Death Differ. 10: 66-75.

11. Sprick MR, Rieser E, Stahl H, Grosse-Wilde A, Weigand MA, Walczak H (2002) Caspase-10 is recruited to and activated at the native TRAIL and CD95 deathinducing signalling complexes in a FADD-dependent manner but can not functionally substitute caspase-8. EMBO J. 21: 4520-4530.

12. Almasan A, Ashkenazi A (2003) Apo2L/TRAlL: apoptosis signaling, biology, and potential for cancer therapy. Cytokine Growth Factor Rev. 14 337-348.

13. Ucur E, Mattern J, Wenger T, Okouoyo S, Schroth A, Debatin KM, Herr I (2003) Induction of apoptosis in experimental human $B$ cell lymphomas by conditional TRAIL-expressing T cells. Br. J. Cancer 89: 2155-2162.

14. Ehrhardt H, Fulda S, Schmid I, Hiscott J, Debatin KM, Jeremias I (2003) TRAIL induced survival and proliferation in cancer cells resistant towards TRAILinduced apoptosis mediated by NF-kappaB. Oncogene 22: 3842-3852.

15. Jin Z, McDonald 3rd ER, Dicker DT, El-Deiry WS (2004) Deficient tumor necrosis factor-related apoptosis-inducing ligand (TRAIL) death receptor transport to the cell surface in human colon cancer cells selected for resistance to TRAIL-induced apoptosis. J. Biol. Chem. 279: 35829-35839.

16. Zhang L, Gu J, Lin T, Huang X, Roth JA, Fang B (2002) Mechanisms involved in development of resistance to adenovirus-mediated proapoptotic gene therapy in DLD1 human colon cancer cell line. Gene Therapy 9: 1262-1270.

17. Trono $D$ (2000) Lentiviral vectors: turning a deadly foe into a therapeutic agent. Gene Therapy 7: 20-23.

18. Wiznerowicz M, Trono D (2005) Harnessing HIV for therapy, basic research and biotechnology. Trends Biotechnol. 23: 42-47.

19. Strehlow D, Jodo S, Ju ST (2000) Retroviral membrane display of apoptotic effector molecules. Proc. Natl. Acad. Sci. USA 97: 4209-4214.

20. Mariani SM, Krammer PH (1998) Differential regulation of TRAIL and CD95 ligand in transformed cells of the T and B lymphocyte lineage. Eur. J. Immunol. 28: 973-982.

21. Monleon I, Martinez-Lorenzo MJ, Monteagudo L, Lasierra P, Taules M, Iturralde M, Pineiro A, Larrad L, Alava MA, Naval J, Anel A (2001) Differential secretion of Fas ligand- or APO2 ligand/TNF-related apoptosis-inducing ligandcarrying microvesicles during activation-induced death of human $\mathrm{T}$ cells. J. Immunol. 167: 6736-6744.

22. Ehrlich S, Infante-Duarte C, Seeger B, Zipp F (2003) Regulation of soluble and surface-bound TRAIL in human T cells, B cells, and monocytes. Cytokine 24: 244-253.

23. Kemp TJ, Ludwig AT, Earel JK, Moore JM, Vanoosten RL, Moses B, Leidal K, Nauseef WM, Griffith TS (2005) Neutrophil stimulation with Mycobacterium bovis bacillus Calmette-Guerin (BCG) results in the release of functional soluble TRAIL/Apo-2L. Blood 106: 3474-3482.

24. Sprick MR, Weigand MA, Rieser E, Rauch CT, Juo P, Blenis J, Krammer PH, Walczak H (2000) FADD/MORT1 and caspase-8 are recruited to TRAIL receptors 1 and 2 and are essential for apoptosis mediated by TRAIL receptor 2. Immunity 12: 599-609.
25. Deng Y, Bennink JR, Kang HC, Haugland RP, Yewdell JW (1995) Fluorescent conjugates of brefeldin A selectively stain the endoplasmic reticulum and Golgi complex of living cells. J. Histochem. Cytochem. 43: 907-915.

26. Hitomi J, Katayama T, Eguchi Y, Kudo T, Taniguchi M, Koyama Y, Manabe T, Yamagishi S, Bando Y, Imaizumi K, Tsujimoto Y, Tohyama M (2004) Involvement of caspase-4 in endoplasmic reticulum stress-induced apoptosis and Abeta-induced cell death. J. Cell Biol. 165: 347-356.

27. Lin T, Gu J, Zhang L, Huang X, Stephens LC, Curley SA, Fang B (2002) Targeted expression of green fluorescent protein/tumor necrosis factor-related apoptosis-inducing ligand fusion protein from human telomerase reverse transcriptase promoter elicits antitumor activity without toxic effects on primary human hepatocytes. Cancer Res. 62: 3620-3625.

28. Lin T, Huang X, Gu J, Zhang L, Roth JA, Xiong M, Curley SA, Yu Y, Hunt KK Fang B (2002) Long-term tumor-free survival from treatment with the GFP. TRAIL fusion gene expressed from the hTERT promoter in breast cancer cells. Oncogene 21: 8020-8028.

29. Lin T, Zhang L, Davis J, Gu J, Nishizaki M, Ji L, Roth JA, Xiong M, Fang B (2003) Combination of TRAIL gene therapy and chemotherapy enhances antitumor and antimetastasis effects in chemosensitive and chemoresistant breast cancers. Mol. Ther. 8: 441-448.

30. Nash KL, Lever AM (2004) Green fluorescent protein: green cells do not always indicate gene expression. Gene Therapy 11: 882-883.

31. Ghosh SK, Wood C, Boise LH, Mian AM, Deyev VV, Feuer G, Toomey NL, Shank NC, Cabral L, Barber GN, Harrington Jr WJ (2003) Potentiation of TRAIL-induced apoptosis in primary effusion lymphoma through azidothymidine-mediated inhibition of NF-kappa B. Blood 101: 2321-2327.

32. Zhang L, Fang B (2005) Mechanisms of resistance to TRAIL-induced apoptosis in cancer. Cancer Gene Ther. 12: 228-237.

33. Medema JP, de Jong J, van Hall T, Melief CJ, Offringa R (1999) Immune escape of tumors in vivo by expression of cellular FLICE-inhibitory protein. J. Exp. Med. 190: 1033-1038.

34. Fulda S, Meyer E, Debatin KM (2002) Inhibition of TRAIL-induced apoptosis by Bcl-2 overexpression. Oncogene 21: 2283-2294.

35. Fulda S, Wick W, Weller M, Debatin KM (2002) Smac agonists sensitize for Apo2L/TRAIL- or anticancer drug-induced apoptosis and induce regression of malignant glioma in vivo. Nat. Med. 8: 808-815.

36. Leverkus M, Sprick MR, Wachter T, Mengling T, Baumann B, Serfling E, Brocker EB, Goebeler M, Neumann M, Walczak H (2003) Proteasome inhibition results in TRAIL sensitization of primary keratinocytes by removing the resistance-mediating block of effector caspase maturation. Mol. Cell. Biol. 23: $777-790$

37. Eggert A, Grotzer MA, Zuzak TJ, Wiewrodt BR, Ho R, Ikegaki N, Brodeur GM (2001) Resistance to tumor necrosis factor-related apoptosis-inducing ligand (TRAIL)-induced apoptosis in neuroblastoma cells correlates with a loss of caspase-8 expression. Cancer Res. 61: 1314-1319.

38. Leverkus M, Sprick MR, Wachter T, Denk A, Brocker EB, Walczak H, Neumann $M$ (2003) TRAlL-induced apoptosis and gene induction in $\mathrm{HaCaT}$ keratinocytes: differential contribution of TRAIL receptors 1 and 2. J. Invest. Dermatol. 121: 149-155.

39. Jobbagy Z, Garfield S, Baptiste L, Eiden MV, Anderson WB (2000) Subcellular redistribution of Pit-2 $\mathrm{P}(\mathrm{i})$ transporter/amphotropic leukemia virus (A-MuLV) receptor in A-MuLV-infected NIH 3T3 fibroblasts: involvement in superinfection interference. J. Virol. 74: 2847-2854.

40. Schneider-Brachert W, Tchikov V, Neumeyer J, Jakob M, Winoto-Morbach S, Held-Feindt J, Heinrich M, Merkel O, Ehrenschwender M, Adam D, Mentlein R, Kabelitz D, Schutze S (2004) Compartmentalization of TNF receptor 1 signaling: internalized TNF receptosomes as death signaling vesicles. Immunity 21: 415-428.

41. Algeciras-Schimnich A, Shen L, Barnhart BC, Murmann AE, Burkhardt JK, Peter ME (2002) Molecular ordering of the initial signaling events of CD95. Mol. Cell. Biol. 22: 207-220

42. Janssen EM, Droin NM, Lemmens EE, Pinkoski MJ, Bensinger SJ, Ehst BD, Griffith TS, Green DR, Schoenberger SP (2005) CD4+ T-cell help controls CD8+ T-cell memory via TRAIL-mediated activation-induced cell death. Nature 434: 88-93

43. Hyer ML, Voelkel-Johnson C, Rubinchik S, Dong J, Norris JS (2000) Intracellular Fas ligand expression causes Fas-mediated apoptosis in human prostate cancer cells resistant to monoclonal antibody-induced apoptosis. Mol. Ther. 2: 348-358 
44. Van Maele B, De Riick J, De Clercq E, Debyser Z (2003) Impact of the centra polypurine tract on the kinetics of human immunodeficiency virus type 1 vector transduction. J. Virol. 77: 4685-4694.

45. Wajant H, Johannes FJ, Haas E, Siemienski K, Schwenzer R, Schubert G Weiss T, Grell M, Scheurich P (1998) Dominant-negative FADD inhibits TNFR60-, Fas/Apo1- and TRAIL-R/Apo2-mediated cell death but not gene induction. Curr. Biol. 8: 113-116.

46. Juo P, Kuo CJ, Yuan J, Blenis J (1998) Essential requirement for caspase-8/ FLICE in the initiation of the Fas-induced apoptotic cascade. Curr. Biol. 8 : 1001-1008.

47. Bak Jr M, Mattern J, Volm M (1987) Maintenance of morphology and tumour marke production in human epidermoid lung carcinoma xenografts. In Vivo 1: 319-326.

48. Herr I, Ucur E, Herzer K, Okouoyo S, Ridder R, Krammer PH, von Knebel Doeberitz M, Debatin KM (2003) Glucocorticoid cotreatment induces apoptosis resistance toward cancer therapy in carcinomas. Cancer Res. 63: 3112-3120.

49. DuBridge RB, Tang P, Hsia HC, Leong PM, Miller JH, Calos MP (1987) Analysis of mutation in human cells by using an Epstein-Barr virus shuttle system. Mol. Cell. Biol. 7: 379-387.

50. Chesebro B, Wehrly K, Nishio J, Perryman S (1992) Macrophage-tropic human immunodeficiency virus isolates from different patients exhibit unusual V3 envelope sequence homogeneity in comparison with T-cell-tropic isolates: definition of critical amino acids involved in cell tropism. J. Virol. 66: 6547-6554

51. Golks A, Brenner D, Fritsch C, Krammer PH, Lavrik IN (2005) c-FLIPR, a new regulator of death receptor-induced apoptosis. J. Biol. Chem. 280: 14507-14513.
52. Scaffidi C, Medema JP, Krammer PH, Peter ME (1997) FLICE is predominantly expressed as two functionally active isoforms, caspase-8/a and caspase- $8 / \mathrm{b}$. J. Biol. Chem. 272: 26953-26958.

53. Naldini L, Blomer U, Gage FH, Trono D, Verma IM (1996) Efficient transfer, integration, and sustained long-term expression of the transgene in adult rat brains injected with a lentiviral vector. Proc. Natl. Acad. Sci. USA 93: 11382-11388.

54. Zufferey R, Dull T, Mandel RJ, Bukovsky A, Quiroz D, Naldini L, Trono D (1998) Self-inactivating lentivirus vector for safe and efficient in vivo gene delivery. J. Virol. 72: 9873-9880.

55. Dhein J, Walczak H, Baumler C, Debatin KM, Krammer PH (1995) Autocrine T-cell suicide mediated by APO-1/(Fas/CD95). Nature 373: 438-441.

56. Salmon P, Kindler V, Ducrey O, Chapuis B, Zubler RH, Trono D (2000) Highlevel transgene expression in human hematopoietic progenitors and differentiated blood lineages after transduction with improved lentiviral vectors. Blood 96: 3392-3398.

57. Kagawa S, He C, Gu J, Koch P, Rha SJ, Roth JA, Curley SA, Stephens LC, Fang B (2001) Antitumor activity and bystander effects of the tumor necrosis factor-related apoptosis-inducing ligand (TRAIL) gene. Cancer Res. 61: 3330-3338.

58. Nicoletti I, Migliorati G, Pagliacci MC, Grignani F, Riccardi C (1991) A rapid and simple method for measuring thymocyte apoptosis by propidium iodide staining and flow cytometry. J. Immunol. Methods 139: 271-279.

Supplementary Information accompanies the paper on Cell Death and Differentiation website (http://www.nature.com/cdd) 